\title{
SNAKEBITE POISONING IN CHILDREN
}

\section{ABSTRACT}

Snakebite Poisoning is a common paediatric emergency especially during the monsoon season in the terai and inner terai regions of Nepal. There is hardly any study conducted so far in Nepal to highlight different aspects of snakebite poisoning in children. This retrospective study was therefore conducted basically to find out the clinicoepidemiological features, case fatality rate and risk factors for death in children admitted in Lumbini Zonal Hospital (LZH) with features of snakebite poisoning.

The study showed the highest incidence of snakebite poisoning among children aged above 10 years. The peak incidence of poisoning was seen during July-August. These months correspond with the monsoon season in Nepal. Most of the victims had bites by unidentified snakes $(75 \%)$, mostly on the fingers \& hands (nearly $50 \%$ ). Nearly $47 \%$ of the children had respiratory distress, and a large majority of them required respiratory support therapy. Case fatality rate (CFR) was nearly $29 \%$. The relative risk factors for death due to snakebite poisoning were: age above 5 years, male sex, bites on the finger \& hand and bites by Kraits. Mortality and morbidity due to snakebite can be reduced by early \& judicious use of anti-snake venom (ASV).

Key Words: Snakebite, Poisoning, Children, Case fatality rate, Nepal.

\section{INTRODUCTION}

Of the more than 3,000 known species of snakes, only 200 are poisonous to humans. ${ }^{1}$ In Nepal, 20 out of 75 species of snakes have been so far reported to be poisonous. ${ }^{2} 90 \%$ of the poisonous snakes belong to one of the three families: Elapidae (Cobras and Kraits), Hydrophidae (Poisonous seasnakes), and Viperidae (true vipers). ${ }^{1}$ The commonest poisonous snakes in the terai and innerterai regions of Nepal are Cobras and Kraits.

Address for correspondence : Dr. Binod M. Shrestha, Paediatrician Lumbini Zonal Hospital, Butwal Nepal. 
Venom from the Elapids is neurotoxic as it blocks the transmission of nerve impulse from the neuromuscular junction. ${ }^{1}$ More than $80 \%$ of bites have been reported to be by non-poisonous snakes. ${ }^{1}$ Incidence of snakebite with or without features of systemic envenomation has been reported to be 4.3 per 1000 population in Nepal. ${ }^{3}$ Even after bites by the poisonous snakes only $50 \%$ of the victims were reported to show the features of systemic envenomation in a study done earlier. ${ }^{4}$ Symptoms of poisoning can rapidly progress in a few hours from mild drowsiness to cranial nerve palsies, weakness and death, which occurs usually from respiratory failure. ${ }^{1}$ Death can, however, occur in some cases from shock due to fright before the poisonous symptoms commence. ${ }^{5}$

\section{MATERIALS AND METHODS}

This retrospective study was conducted in those 73 children, who had clinical features of snakebite poisoning and were brought in the emergency of Lumbini Zonal Hospital during the 24 months period from April, 2000 to April, 2002. Lumbini Zonal Hospital is 136-bedded peripheral hospital, which renders health services to the people of as many as 12 out of 75 districts of Nepal. It is rapidly developing as an accessible secondary referral health centre in the western and mid-western regions of the country.

All the 73 case files were reviewed, and data were analyzed for age, sex, ethnicity, seasonal pattern, biting sites, types of biting snakes, time of biting, clinical features, numbers of vials of antivenom (ASV) used during treatment, outcome and risk factors for death etc.

\section{RESULTS}

Analysis of data revealed the following findings:

\section{Monthly incidence}

- Period of study = 24 months

- Total number of poisoning cases $=73$

- Average number of cases per month $=3.0$

\section{Age incidence}

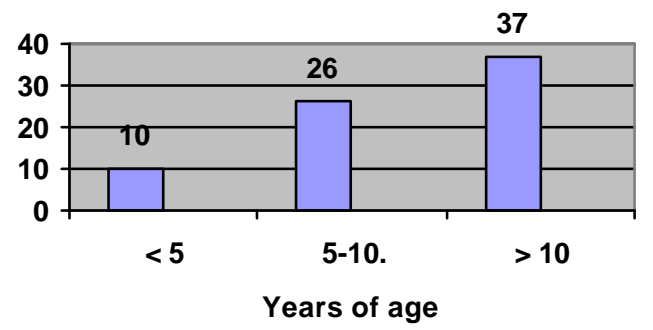

Incidence of snakebite poisoning was highest among children aged above 10 years $(51 \%)$, and lowest among children below 5 years (14\%). The youngest child was a 10 month old girl.

\section{Sex incidence}

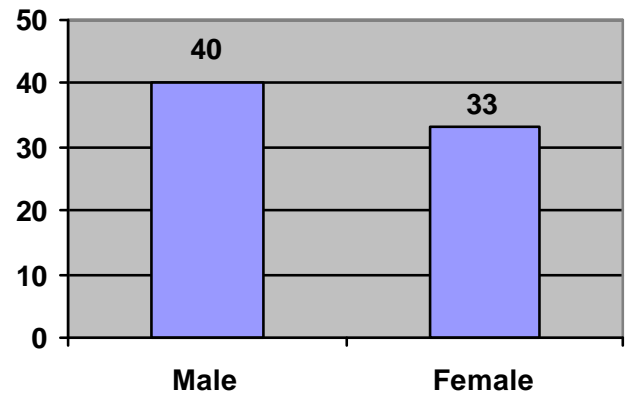

Incidence of poisoning was slightly more in boys than in girls. 


\section{Seasonal incidence}

About one third of cases occures during the month of July and August.

\section{Biting snakes}

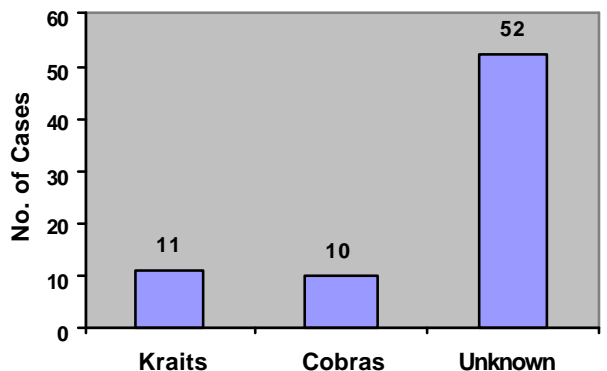

In the majority of cases $(71.2 \%)$ the biting snakes could not be identified. However, among the identified snakes; incidence of Cobra bite was almost equal to those of Krait bite.

\section{Biting sites}

In the majority of cases (nearly 50\%), the biting sites were the finger $\&$ hand. About $10 \%$ of cases, the biting site was foot. In $20 \%$ of case notes, the site was not mentioned.

\section{First-aid measures}

No first aid measures were applied in $56 \%$ of cases. Tourniquets were used as first-aid measures in $42.5 \%$ of cases. Crepe bandage was used in only one case.

\section{Frequency of symptoms \& signs}

Ptosis was the commonest $(96.5 \%)$ clinical finding. Respiratory distress was present in $47 \%$ cases; and a large majority of them needed respiratory support. Dysphagia was observed in $10 \%$ of cases.
9. Number of ASV vials used during treatment

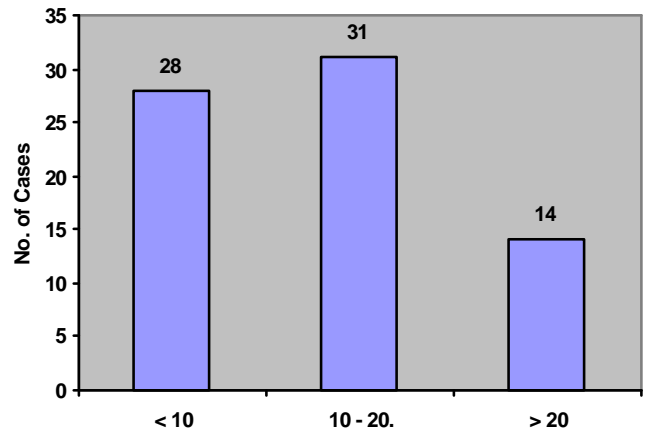

Number ofASV vials used during treatment ranged from 1 to 42. Average number of vials used was 14.4 per case. In $19.2 \%$ poisoning cases more than 20 vials has been used.

\section{Prognosis \& outcome}

The case fatality rate among the poisoning cases was $28.8 \%$.

A six-year old girl brought in the emergency after 10 hours of bite, who received 42 vials of antisnake venom survived.

\section{DISCUSSION}

The present study has clearly shown the highest incidence of snakebite poisoning among children over 10 years. Children of this age group in Terai are given responsibility to carry out outdoor activities such as grass-cutting, firewood-collecting and field-working. These works expose them to snakebite. Incidence of poisoning was slightly higher in boys than girls in this study $(55 \%$ vs $45 \%$ ). This is probably due to the confinement of the girls in-door activities like cooking food. 
In this study, the highest incidence of snakebite poisoning was seen during the months of July and August. These months, in fact coincide with the monsoon season in Nepal, when the snakes are compelled to come out of their shelter because of the increased humidity and temperature. This characteristic seasonal pattern of poisoning was seen in other studies as well.

The large majority of children (71\%) could not identify the biting snake. This is possibly because of poor knowledge of children about snakes, poor visibility and bite during night.

In the majority of cases (nearly 50\%) the biting sites were the fingers and hands. This is possible because the curious young children, while playing, put their fingers and hands into the blind holes or pits where the poisonous snakes can hide in. Similarly the older children happen to touch the snakes while cutting the grass. This finding is in contrast to the findings of the earlier studies where the most frequent biting site was the lower extremity. ${ }^{3,7}$ The explanation given was that the snake had been accidentally stamped while walking.

Tourniquets were the common first-aid measures $(42 \%)$ used by the caretakers. People believe that tying of the limb proximal to the biting site prevents the spread of venom into the vital organs. However, none of the patients had gangrene. This is probably due to the early presentation to the hospital. About $68 \%$ of patients had presented to the hospital in less than 2 hours of snakebite. People are becoming aware of the fact that early treatment is necessary for recovery or survival.

The commonest $(96.5 \%)$ clinical finding in the present study was Ptosis, which occurs as a result of ocular muscle palsy by the neurotoxin in the venom. Ptosis is easily noticeable both by the parents and the health workers. Respiratory distress was observed in approximately $47 \%$ of children; and a large majority of them needed respiratory support therapy. Respiratory distress, which is mostly as a result of paralysis of muscles of respiration by the neurotoxin, develops when the treatment of the poisoning is either too much delayed or inadequate.

In the present study, majority of victims (42\%) needed 10-20 vials of ASV during treatment. About $20 \%$ of the victims needed more than 20 vials. The average number of vials of ASV used during treatment was 14.4 per case. This is comparable to another study where the number of vials used was 19.6/case. ${ }^{3}$ The decision to use ASV, however, depends on the severity and progression of symptoms. Children often require more ASV than a similarly envenomated adult because of their small volume-to-volume ratio.

So far the case fatality rate (CFR) is concerned, it was quite high (29\%) in this study. This is in large contrast to the earlier studies where the CFR varied from none to $4.5 \%{ }^{2,3}$ This high CFR in this study is because of the fact that children are at greater risk of severe envenomation on account of their smaller size or volume for venom distribution. Secondly, in this study, only the poisanous snakebite cases have been included.

\section{CONCLUSION AND RECOMMENDATION}

- Snakebite poisoning is a common childhood emergency in the terai and inner-terai regions of Nepal, especially during monsoon. It is therefore essential to have a good stock of vials of ASV in the hospitals in those regions.

- Bilateral ptosis, the commonest clinical feature, should be considered as a diagnostic sign of snakebite poisoning; its mere presence means that the patient needs an urgent treatment 
- Respiratory distress, often a common clinical finding in snakebite poisoning is an early sign of respiratory failure. It is therefore necessary to have a trained health worker with an appropriate resuscitation-set all the time in the emergency room.

- The morbidity and mortality due to snakebite poisoning can be minimized by early and judicious use of appropriate ASV. However, ASV must be used discretely upon manifestations of systemic envenomation, since it is quite costly and not easily available.

- It is better to counsel the older patients and their attendants while in the hospital emphasizing about the measures of prevention from snakebite. Imparting health education to the attendants about the harmful practices, such as the traditional faith-healing treatment of poisoning is an equally important task of the heath workers.

\section{ACKNOWLEDGMENT}

I would like to thank our medical superintendent for allowing me to review the record files and Mr. Meen B. Somai for his secretarial help.

\section{REFERENCES}

1. $H$ olve $S . E$ nvenomation: I $n B$ ehrman $R E, K$ liegman $R M$ and J enson $H B$ (eds). $N$ elson $T$ extbook of $P$ ediatrics. $16^{\text {th }}$ edn, W .B. S aunders company 2000:2174 - 78 .

2. W arrel $D A, O$ 'S hea $M . S$ nakes $\&$ S nakebite in $N$ epal. T ropical D octor 1998: 28; 223-26.

3. D evkota $U N, S$ teinman $J P, K$ athayat $J B$. E pidemiology of snakebite; $A$ study from $C$ hoharwa A rmy C amp, S iraha, $N$ epal. J ournal of the $N$ epal M edical A ssociation (J N M A ). 2001,40; 57-62.

4. $\quad H$ eap B J,C owan $G O$. T he epidemiol ogy of snakebite presenting to $B$ ritish $M$ ilitary $H$ ospital, D haran, during 1989. I R A rmy M ed C orps, 1991 :vol. 137; $123-125$.

5. Subrahmanyam B V. M odi's M edical J urisprudence and T oxicology: $22^{\text {nd }}$ edition. $B$ utterworths, I ndia; 1999;S ection 2,C hapter 6: pp $264-271$.

6. B ewes $P, H$ olmgren $G, S$ nakebite in $E$ ast and $S$ outhern A frica. $\mathrm{N}$ ytt. $0 \mathrm{~m} \mathrm{U}$-landshal sovard.1997. vol. 2; 4-8.

7. W arrel $D A, W H O / S E A R O$ guidelines for the clinical management of snakebites in the $S$ outh E ast A sian R egion. 1999. vol. 30.

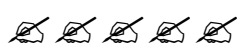

